\title{
APPROPRIATELY SIZED GENERA AND APPROPRIATELY RANKED HIGHER TAXA
}

\section{T} here are some truly pressing problems for systematic mycology, for example, "What should be done about fungi known only from environmental DNA sequences (Hibbett et al. 2011, Hibbett \& Taylor, 2013)?" or, "Is a population any different from a species when both are genetically differentiated in nature and each possesses unique adaptive phenotypes (Ellison et al. 2011, Neafsey et al. 2010)?" These are problems that can be solved by objective research, so I am not going to say any more about them. Instead, I want to explore the current buzz about naming taxa above the species level, which is a problem of a more subjective nature and which was the topic of the recent 2014 CBS Spring Symposium on "Genera and Genomes" (http://www.cbs.knaw.nl/index.php/ meetings/396-2014-cbs-spring-symposiumthe-genera-of-fungi).

Two taxonomic issues bother me - those of inappropriately large genera and that of taxa of inappropriately elevated rank. Beginning with genera, one might ask, "Is there an appropriate size for a genus and, if so, what should it be?" The taxonomic study that helped precipitate the onefungus-one-name revolution began with a large sexual (teleomorph-typified) genus, Botryosphaeria, and used DNA variation along with sexual and asexual (anamorph) reproductive characters to sort it into 12 genus-level clades, one of which retained the original name (Crous et al. 2006). Subsequently, similar work was done using fungi with Fusarium asexual morphs, this time using DNA variation to identify multiple clades and then examining sexual characters to sort them into species, while retaining Fusarium for the clade that harboured the type specimen (Grafenhan et al. 2011, Schroers et al. 2011). Not many fusariologists were happy with this outcome, and a counter proposal was published arguing that the genus Fusarium should be kept large to acknowledge, among other things, its social importance (Geiser et al. 2013). Another large, lonmg-established genus, Penicillium, was also examined and found to be too large because Aspergillus and other genera lay between its two large clades, one having and one lacking Talaromyces sexual morphs. Here, the authors neatly restored monophyly, without argument, by applying Penicillium to one group and Talaromyes to the other (Houbraken \& Samson 2011). However, in their Penicillium study, those authors also argued that Aspergillus should be kept as a large genus. This suggestion has been contested by a recent study showing that fungi with Aspergillus asexual morphs can be sorted into several smaller genera, each embracing phylogenetic diversity similar to that of the recently narrowed Penicillium, and each congruent with genera based on sexual morphs that were previously described to accommodate their distinct morphologies and physiologies (Pitt \& Taylor 2014). If a trend can be drawn from these few examples, it might be that there is sentiment to keep large genera when they are socially important and share an easily recognized, ancestral, asexual morph. Admittedly, there are benefits to larger genera, but there are also drawbacks. As noted by Grafenhan et al. (2011), when speaking of two large clades of fungi with Fusarium anamorphs, "... the amount of morphological diversity incorporated in both of these large clades was huge, rendering the resulting taxonomy meaningless from a practical point of view." The task for mycologists is to define genera that are scientifically meaningful and, at the same time, politically useful. Where that task seems impossible, should we err

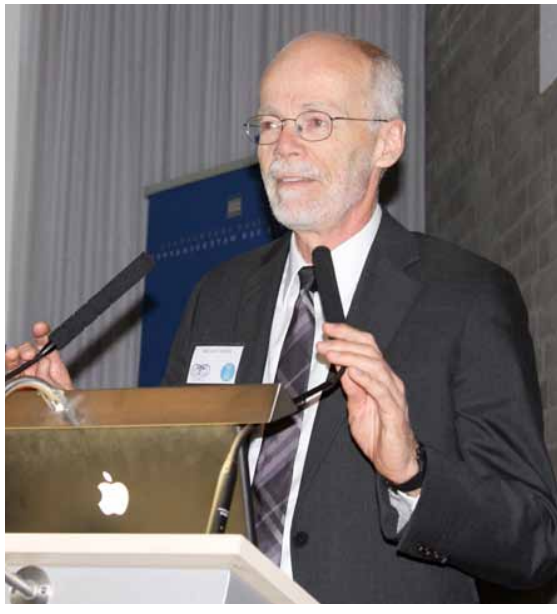

on the side of scientific meaning? As these debates play out, it is calming to remember that nomenclature follows taxonomy, and if today's inappropriately large genus is divided tomorrow, the names for the smaller genera will still be available for each of them.

I am reminded of the second issue, that of appropriate taxonomic rank, each time I teach mycology. It's a problem that is nicely illustrated by observing Fig. 1 taken from the current, "Classification of Fungi" (Hibbett et al. 2007). Here, all fungal phyla and even some subphyla radiate directly from the base of the Fungi, with one exception. That exception is the phylum of rumen fungi, Neocallimastigomycota, which emerges from a branch that it shares with Chytridiomycota. Why, students ask, is Neocallimastigomycota a phylum when it might better be a subphylum or class of Chytridiomycota? To answer, I tell them about the unusual niche and exceptional phenotypes of rumen fungi. But, as I do so, I know that we mycologists have let phenotype wrongly dictate taxonomic level. By the time the class reaches Basidiomycota, those same students raise the same question

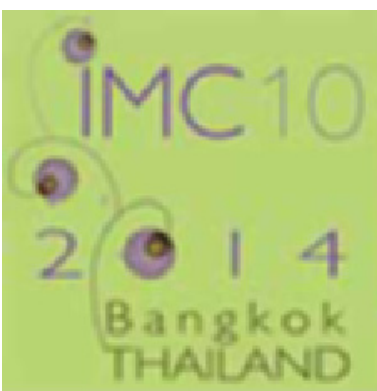

\section{The $10^{\text {th }}$ International Mycological Congress in Bangkok, THAllAND AUGUST 3 TO 8, 2014}

www.imc10.com 


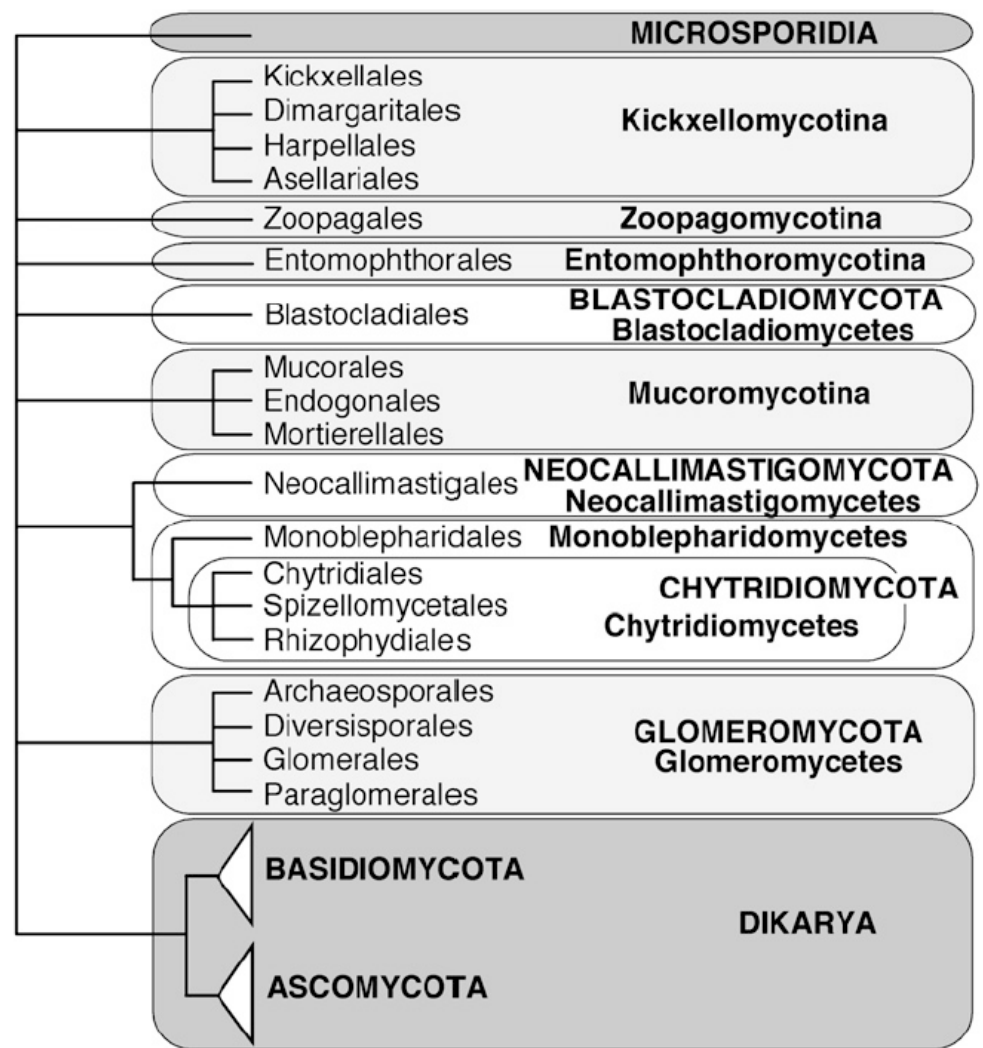

Fig. 1. Position of Neocallimastgomycota. Reproduced from Hibbett $e$ t al. (2007).

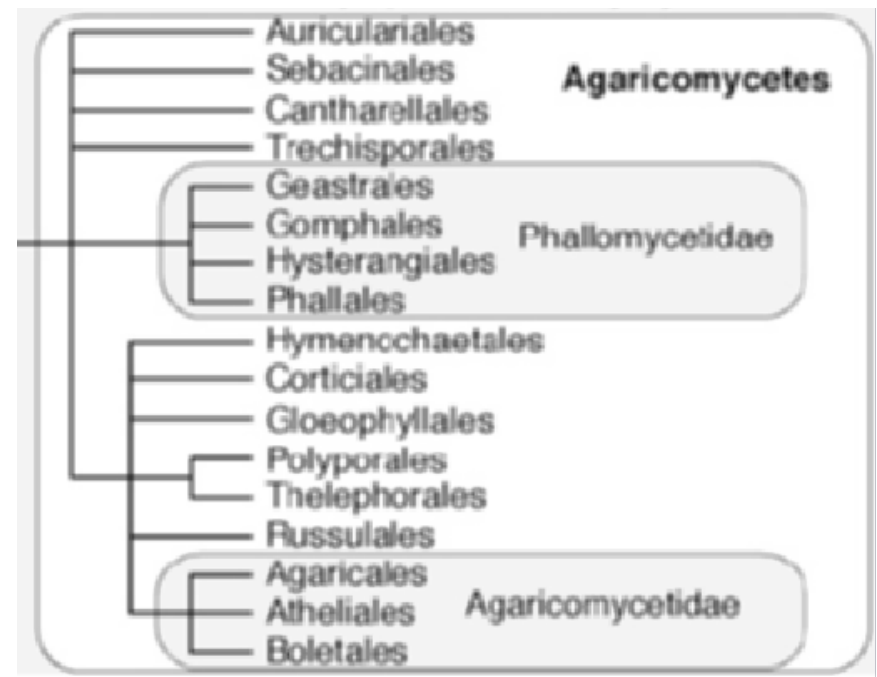

Fig. 2. Position of Phallomycetidae. Reproduced from Hibbett et al. (2007).

about the Phallomycetidae, seen in Fig. 2 taken from the "Classification of Fungi" (Hibbett et al. 2007, fig. 2). Now that it is late in the semester (and now that I have tired of defending these lapses in mycological logic), I generally admit that this subclass ought to be an order, and that its elevation stems, again, from its remarkable phenotypes, evolved this time through dispersal by animals. In these cases of wrongly elevated rank, it seems that one distinctive phenotype has trumped the phylogenetic signal of thousands of genetic differences. The next time that the classification of fungi is revised, those of us who teach mycology ask that taxa are assigned to their appropriate rank, at least where possible.

Crous PW, Slippers B, Wingfield MJ, Rheeder J, Marasas WFO, et al. (2006) Phylogenetic lineages in the Botryosphaeriaceae. Studies in
Mycology 55: 235-253.

Ellison CE, Hall C, Kowbel D, Welch J, Brem R B, Glass N L, Taylor JW (2011) Population genomics and local adaptation in wild isolates of a model microbial eukaryote. Proceedongs of the National Academy of Sciences, USA 108 2831-2836.

Geiser DM, Aoki T, Bacon CW, Baker SE, Bhattacharyya MK, et al. (2013) One fungus, one name: defining the genus Fusarium in a scientifically robust way that preserves longstanding use. Phytopathology 103: 400408.

Grafenhan T, Schroers HJ, Nirenberg HI, Seifert KA (2011) An overview of the taxonomy, phylogeny, and typification of nectriaceous fungi in Cosmospora, Acremonium, Fusarium, Stilbella, and Volutella. Studies in Mycology 68: 79-113.

Hibbett DS, Binder M, Bischoff JF, Blackwell M, Cannon PF, et al. (2007) A higher-level phylogenetic classification of the Fungi. Mycological Research 111: 509-547.

Hibbett DS, Ohman A, Glotzer D, Nuhn M, Kirk P, Nilsson RH (2011) Progress in molecular and morphological taxon discovery in Fungi and options for formal classification of environmental sequences. Fungal Biology Reviews 25: 38-47.

Hibbett DS, Taylor JW (2013) Fungal systematics: is a new age of enlightenment at hand? Nature Reviews, Microbiology 11: 129-133.

Houbraken J, Samson RA (2011) Phylogeny of Penicillium and the segregation of Trichocomaceae into three families. Studies in Mycology 70: 1-51

Neafsey DE, Barker BM, Sharpton TJ, Stajich JE, Park DJ, et al. (2010) Population genomic sequencing of Coccidioides fungi reveals recent hybridization and transposon control. Genome Research 20: 938-946.

Pitt JI, Taylor JW (2014) Aspergillus, its sexual states, and the new International Code of Nomenclature. Mycologia [Preliminary version published online 28 May 2014]: doi:10.3852/14-060.

Schroers HJ, Grafenhan T, Nirenberg HI, Seifert KA (2011) A revision of Cyanonectria and Geejayessia gen. nov., and related species with Fusarium-like anamorphs. Studies in Mycology 68: 115-138.

John W. Taylor

President, IMA

Department of Plant and Microbial Biology University of California, Berkeley, CA 94720-3102, USA (e-mail: jtaylor@berkeley.edu) 